Onkologe 2019 $\cdot 25: 488$

https://doi.org/10.1007/s00761-019-0556-7

Online publiziert: 12. März 2019

(c) Springer Medizin Verlag GmbH, ein Teil von Springer Nature 2019

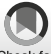

Peter Hallscheidt

Radiologie Darmstadt, Fachärztezentrum am Klinikum, Darmstadt, Deutschland

\title{
Erratum zu: Bildgebung bei Nierenzellkarzinom
}

\section{Erratum zu:}

Onkologe 2019

https://doi.org/10.1007/s00761-0190536-y

Leider sind durch ein Versehen die Legenden der $\bullet$ Abb. 2 und 3 vertauscht worden. Nachstehend sehen Sie die beiden Abbildungen mit den richtig zugeordneten Legenden. Der Originalbeitrag wurde korrigiert. Wir bitten den Fehler zu entschuldigen.

\section{Korrespondenzadresse}

Prof. Dr. Peter Hallscheidt

Radiologie Darmstadt, Fachärztezentrum am Klinikum

Grafenstraße 13, 64283 Darmstadt,

Deutschland

hallscheidt@yahoo.de

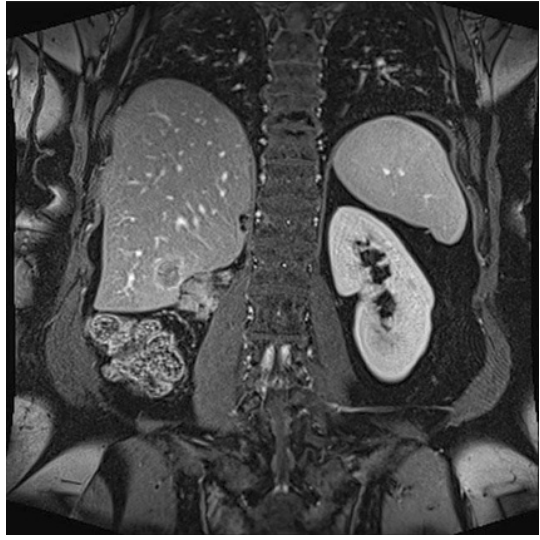

Abb. $2 \Delta$ Lokalrezidiv nach Tumorresektion in der rechten Niere mit Leberinfiltration

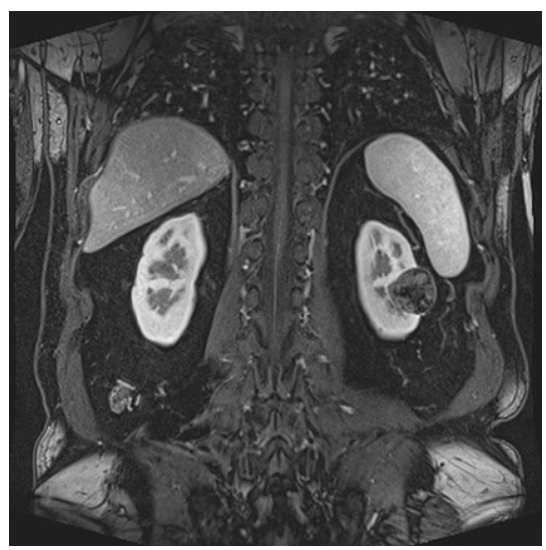

Abb. 3 ॥ Angiomyolipom in der fettsupprimierten Sequenz mit Signalverlust der Fettanteile in der linken Niere 